\title{
Fragmentação da Paisagem na Região Metropolitana de Aracaju-SE, Brasil
}

Landscape Fragmentation in the Metropolitan Region of Aracaju-SE, Brazil

\author{
Gabriela Bispo Valenzuela ${ }^{1}$ \\ Rodrigo Mikosz Gonçalves ${ }^{2}$ \\ Paulo Henrique Gomes de Oliveira Sousa ${ }^{3}$ \\ Heithor Alexandre de Araujo Queiroz ${ }^{4}$
}

Recebido em janeiro de 2019.

Aprovado em setembro de 2019.

\begin{abstract}
RESUMO
O objetivo deste artigo é analisar a fragmentação da paisagem e sua evolução temporal considerando um intervalo de 25 anos (1990 e 2015) para a região metropolitana de Aracaju, Sergipe, Brasil. Como materiais foram utilizadas imagens de satélites LANDSAT 5 e 8. As imagens foram classificadas pelo método supervisionado conforme a seleção de sete classes de uso do solo, sendo elas: Floresta, Mangue, Restinga, Cultivo e/ou Pastagem, Solo Exposto, Adensamento Urbano e Corpos D'Água. As validações das classificações foram feitas através da análise da matriz de confusão e do cálculo do índice Kappa. A partir desta classificação, foram calculadas sete métricas à nível de fragmento (área total da classe, porcentagem da classe na paisagem, número de fragmentos por classe, densidade de fragmentos, tamanho médio do fragmento por classe, índice de proximidade médio, distância média até o vizinho mais próximo). Os resultados obtidos indicam que a área de estudo se encontra com transformações estruturais da paisagem desde 1990 e apresenta alto grau de fragmentação das áreas de vegetação natural (Floresta, Mangue e Restinga) sendo sobrepostas por classes relacionadas ao uso antrópico, principalmente no que diz respeito ao uso urbano e às atividades agropastoris.
\end{abstract}

PALAVRAS-CHAVE: Fragmentação da paisagem. Ecologia da paisagem. Uso do solo. Sensoriamento Remoto.

\footnotetext{
${ }^{1}$ Universidade Federal de Pernambuco - Laboratório de Cartografia Costeira (LACCOST). E-mail: gbvalenz.geo@gmail.com

2Universidade Federal de Pernambuco - Laboratório de Cartografia Costeira (LACCOST). E-mail: rodrigo.mikosz@gmail.com

${ }^{3}$ Universidade Federal do Ceará, Instituto de Ciências do Mar. E-mail: sousaph@gmail.com

${ }^{4}$ Instituto Nacional do Semiárido (INSA). E-mail: heithorqueiroz@gmail.com
} 


\begin{abstract}
The present study aims to analyze the landscape fragmentation and its temporal evolution considering an interval of 25 years (1990 and 2015), for the metropolitan region of Aracaju, Sergipe, Brazil. The satellite images LANDSAT 5 and 8 were used as materials. The images were classified using supervised method, according to seven land use/land cover classes, which are Forest, Mangrove, Sand-dune, Agriculture and/or Pasture, Bare Soil, Urban Area and Water Bodies. The classification validation was assessed by the Confusion Matrix and Kappa index. From this classification, seven landscape metrics were calculated as fragment level (class area, percentage of landscape, number of patches, patch density, mean area of fragments, average proximity index and nearest neighbor distance). The results indicate that since 1990 the study area is under a landscape transformation processes, and reveals a high fragmentation degree considering the natural vegetation areas (Forest, Mangrove and Sand-dune) that have been replaced by anthropogenic features, such as those related to the urban use and grazing activities.
\end{abstract}

KEYWORDS: Landscape fragmentation. Landscape ecology. Land use land cover. Remote Sensing.

\title{
Introdução
}

Assim como em outras regiões costeiras ao redor do mundo, o litoral brasileiro é marcado pelo desenvolvimento de importantes atividades econômicas, elevado contingente populacional e conflitos em relação ao seu uso e ocupação. Desta maneira, as consequências do crescimento das cidades, o uso desordenado do solo e a expansão urbana acelerada, se tornaram um problema que merece destaque na sociedade atual (MORAES, 2007). Adicionalmente, Andrés, Barragán e Scherer (2018) sugerem que as ferramentas para gestão e planejamento da zona costeira deveriam abranger uma região maior que englobe também a área onde as atividades econômicas relacionadas ao ambiente marinho estejam mais presentes.

Para detectar os efeitos dessas transformações e acompanhar as mudanças decorrentes da interação entre a sociedade e a natureza, a ecologia de paisagem, através do uso de métricas, propõe o estabelecimento de padrões espaciais que permitem compreender as unidades da paisagem bem como quantificar sua estrutura (TURNER et al., 1989). As métricas da paisagem 
são índices que fornecem o suporte científico para evidenciar o grau de fragmentação da paisagem, ou seja, o quanto a paisagem original foi fragmentada pelas distintas classes de usos do solo. Dentre os primeiros trabalhos desenvolvidos nessa temática, destacam-se os estudos de Troll (1950), que introduziu em 1939, o termo Ecologia da Paisagem e sua definição, Forman e Gordon (1986), que apresentaram a estruturação da paisagem, além de Turner et al., (1989), que retrataram os estudos de análise dos padrões espaciais encontrados na paisagem e McGarigal e Marks (1995), os quais destacaram os estudos da paisagem através do cálculo de índices, contribuindo desta forma com a definição das métricas da paisagem. Recentemente, estudos relacionados à fragmentação da paisagem apontam a importância da técnica para ações de planejamento, gestão e conservação de recursos naturais (LAM et al., 2018; DESMET, 2018; KUMAR et al., 2018).

No Brasil, também existem pesquisas relacionadas à aplicação das métricas da paisagem, como por exemplo estudos voltados à recuperação de áreas degradadas (JESUS et al., 2015; AZEVEDO, GOMES e MORAES, 2016; CAMELO e SANCHES 2016; FERNANDES et al., 2017), que analisam a estrutura da paisagem no presente e tem como enfoque maneiras de reestabelecimento do equilíbrio ou a conservação das áreas de estudo (COELHO et al., 2018; OLIVEIRA et al., 2019; LIMA et al., 2019, LEAL et al., 2019).

No entanto, são escassos os estudos que propõem análises de séries temporais, para investigar a dinâmica temporal, na busca por padrões que possibilitem compreender a natureza das transformações no uso do solo. Assim, a metodologia desenvolvida neste trabalho propõe a integração de técnicas de sensoriamento remoto às métricas espaciais, para examinar diferentes dimensões estruturais de mudanças no uso do solo, como localização, distribuição e tamanho dos fragmentos, que são importantes variáveis para a quantificação e compreensão da estrutura da paisagem. Entretanto, há de se destacar dois desafios a serem superados, o primeiro deles é a utilização de dados de média resolução espacial para a identificação 
de tais mudanças. O segundo desafio é a utilização de dados provenientes de sensoriamento remoto em áreas costeiras, visto a dificuldade de encontrar imagens cujo recobrimento de nuvens permita a aplicação desta metodologia.

A área de estudo proposta por essa pesquisa compreende a região metropolitana de Aracaju, no Estado de Sergipe, onde a paisagem sofreu grandes modificações nos últimos anos, apresentando contrastes significativos em suas características. Além disso, a presença de feições geomorfológicas frágeis, com alta variabilidade natural, onde estão ocorrendo as principais mudanças estruturais no uso e ocupação do solo, vêm aumentando os riscos de consequências irreversíveis, e consequentemente exigindo atenção por parte dos gestores (OLIVEIRA e SOUZA, 2017). Assim, é de extrema importância o desenvolvimento de pesquisas que possam detectar mudanças e classificar o uso do solo de forma eficaz, podendo demonstrar a evolução dos últimos 25 anos, além de gerar dados que contribuam para o prognóstico de cenários futuros.

\section{1 Área de estudo}

A Região Metropolitana de Aracaju (RMA) foi criada pela Lei Complementar Estadual no 25, de 29 de dezembro de 1995. Em seu Art. 2 consta que a Região Metropolitana de Aracaju apresentada na Figura 1 (c), é constituída pelo agrupamento dos municípios de Aracaju, São Cristóvão, Nossa Senhora do Socorro e Barra dos Coqueiros e possui uma população estimada em 835.816 habitantes (IBGE, 2017), distribuídos numa área de aproximadamente $864.510 \mathrm{~km}^{2}$. Sua criação se deu com vistas à realização, de forma integrada, das ações de organização, de planejamento e de execução de funções públicas do interesse comum.

No tocante aos aspectos físicos, o Estado de Sergipe (Figura 1a) está inserido na unidade geotectônica Bacia Sedimentar Sergipe/Alagoas e litologias associadas ao Grupo Barreiras e Formações Superficiais Cenozóicas 
(SANTOS et al., 1998), resultantes de variações do nível do mar e episódios de regressão e transgressão marinha (BITTENCOURT et al., 1983).

A geomorfologia da área de estudo é composta, principalmente, pelas unidades geomorfológicas Planície Costeira (terraços marinhos holocênicos, depósitos de mangue e depósitos eólicos) e Tabuleiros Costeiros, caracterizados por solos profundos e de baixa fertilidade (EMBRAPA, 2014). Os aspectos fitogeográficos são compostos por: floresta ombrófila, floresta estacional, mangue e vegetação de restinga (BRASIL, 2006).

Com relação às características climatológicas, a área de estudo apresenta clima predominantemente quente e úmido, com temperaturas médias anuais de $27^{\circ} \mathrm{C}$. No tocante à precipitação pluviométrica, a média anual é de, aproximadamente, $1.600 \mathrm{~mm}$ (SRH, 2016), com concentração de chuvas nos meses de março a agosto. Na Orla Marítima de Aracaju, os ventos são provenientes de Nordeste, Leste e Sudeste, sendo que os ventos de SE ocorrem no período chuvoso e os ventos de NE e E, no período seco (INMET, 2016). 
Figura 1 - (a) Localização de Sergipe em relação ao Nordeste. (b) Destaque da Região Metropolitana de Aracaju (RMA) em Sergipe. (c) Municípios componentes da RMA
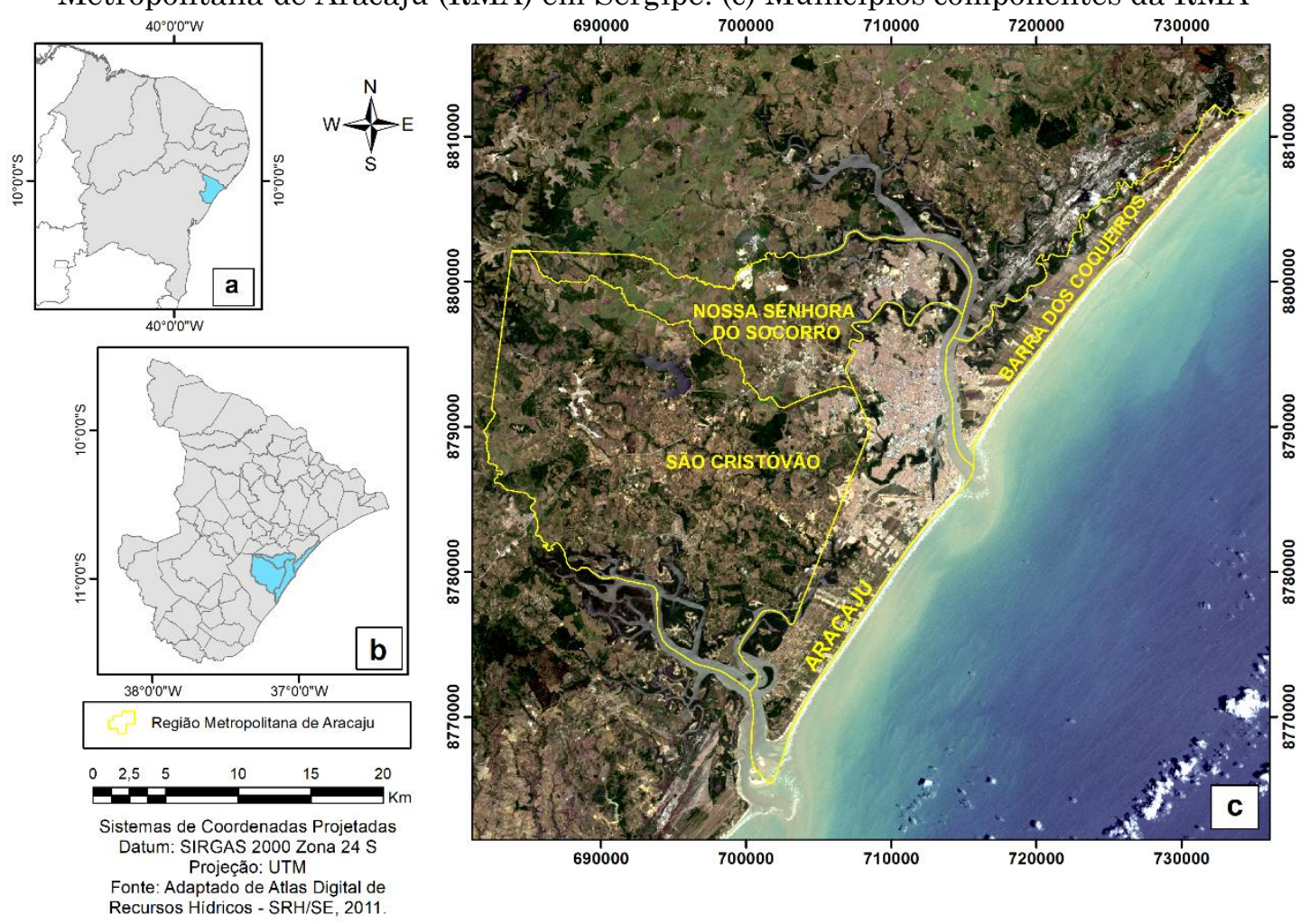

Fonte: Elaborada pelos autores.

Nos quatro municípios que compõem a área de estudos, Sergipe (2011) mapeou 15 tipos distintos de uso do solo. Destes, caracterizam-se como aspectos fitogeográficos a Floresta Ombrófila - formação vegetal típica de clima úmido e associadas às altitudes do Grupo Barreiras; Floresta Estacional - vegetação adaptada a um ritmo estacional; Mangue, cuja vegetação se dá em ambientes costeiros sob forte influência de oscilação de marés, como o caso das espécies Rhizophora mangle, Laguncularia racemosa, Avicennia germinans e Avicennia schaueriana, que são facilmente encontradas na área de estudo; e Vegetação de Restinga com espécies que recebem influência marinha direta e são capazes de colonizar areias desnudas fixando-as solidamente (BRASIL, 2006). Estes e outros tipos de uso do solo podem ser observados na Figura 2, conforme visita em campo para o reconhecimento das classes de uso do solo utilizados nesta pesquisa. 
Figura 2 - Alguns tipos de uso do solo encontrados na área de estudo. A - Área de Pastagem em vertentes no município de Nossa Senhora do Socorro; B - Manguezal às margens do rio Santa Maria, entre os municípios de Aracaju e São Cristóvão. C - Curso d'água do rio Vaza Barris na região limítrofe dos municípios de Aracaju e São Cristóvão; D

- Vegetação de Restinga fixando as areias das dunas, ao fundo o cultivo de coco no município de Barra dos Coqueiros; E - Área de Floresta Ombrófila encontrada dentro da APA do Morro do Urubu, em Aracaju; F - Região do Centro de Aracaju, vista de Barra dos Coqueiros

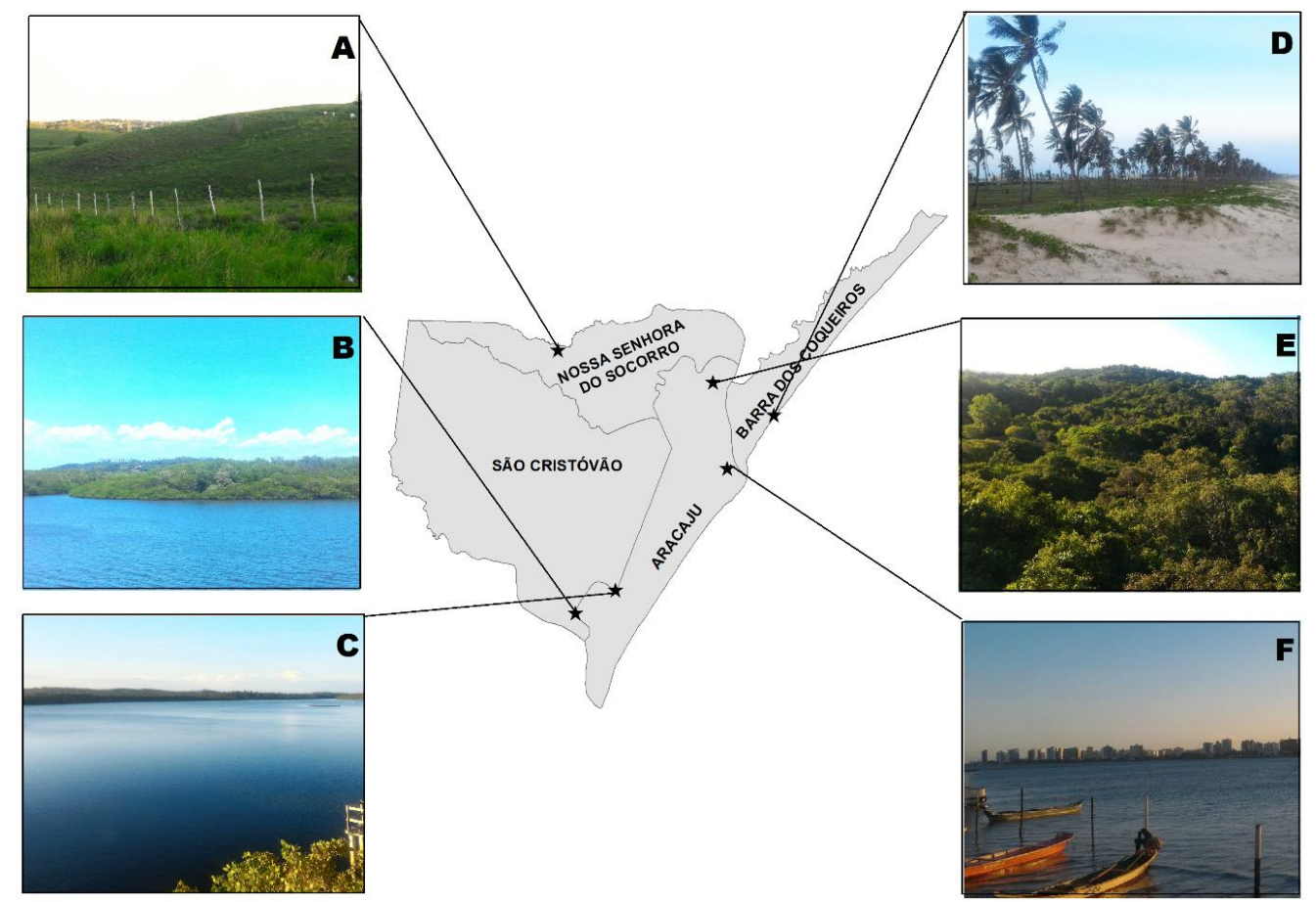

Fonte: Elaborada pelos autores.

Com relação às características hidrográficas, a área de estudo está sob influência e é abastecida pelos canais das Bacias Hidrográficas do Rio Sergipe e Vaza-Barris, contanto com 9 fontes de captação. Além disso, o controle de chuvas é proporcionado pela Barragem do Poxim-Açu, pertencente à Bacia Hidrográfica do Rio Sergipe, e ao Rio Paramopama, afluente do rio VazaBarris.

Ao analisar o Atlas Digital elaborado por Sergipe (2011), dentre os outros tipos de uso encontrados na área destacam-se a presença de 4 Unidades de Conservação - APA Morro do Urubu (Aracaju), Parque Municipal Ecológico do Tramandaí (Aracaju), Paisagem Natural Notável (Aracaju/Barra) e Floresta Nacional do Ibura - FLONAI (Socorro), o Parque 
Eólico de Barra dos Coqueiros, que é constituído por vinte e três unidades aerogeradoras totalizando 34,5 MW de capacidade instalada, a presença de uma comunidade quilombola urbana - A Maloca, e 11 (onze) indústrias relacionadas à extração e manipulação mineral.

\section{Materiais e Métodos}

Foram utilizadas imagens provenientes do LANDSAT 5, sensor TM, data: 11/12/1990, órbita: 215, pontos: 067 e 068; e LANDSAT 8, sensor OLI, data: 16/11/2015 órbita: 215, pontos: 067 e 068. Os critérios de seleção foram baseados na baixa quantidade de nuvens e no enquadramento que recobre a área de estudo. Ambas obtidas através do catálogo de imagens do Instituto Nacional de Pesquisas Espaciais (INPE), porém, também podem ser encontradas no site da United States Geological Survey (USGS). Para o registro das imagens e a geração do mosaico, foi utilizado o software ArcGIS versão 10.1 (ESRI). Já para os processamentos de composição RGB e classificação, foi utilizado o software Spring versão 5.2.7 (INPE). A aplicação das métricas foram executadas utilizando o software Fragstats versão 4.2 (MCGARIGAL e MARKS, 1995) e a tabulação dos dados foi executada em planilhas eletrônicas.

A metodologia para análise da fragmentação da paisagem consiste em índices numéricos que podem quantificar os atributos espaciais da paisagem e compreender o funcionamento da sua dinâmica, são as métricas da paisagem (VOLOTÃO, 1998). Assim, as métricas são executadas tomando como base norteadora os princípios da Ecologia da Paisagem (METZGER, 2006) e sua estrutura, cuja divisão consiste em: Mancha, Corredor e Matriz (FORMAN e GODRON, 1986). Tendo em vista que o objetivo principal das métricas é possibilitar uma análise quantitativa dos padrões espaciais da paisagem, bem como entender como se dá o desenvolvimento da dinâmica espacial que a compõe, estão inseridos os índices, que se baseiam na distribuição, forma e arranjo espacial dos fragmentos. Assim, a quantificação 
pode ser feita em três níveis de análise, sendo eles: a resolução de cada fragmento, a escala da classe e a escala da paisagem total.

Partindo disso, o desenvolvimento deste estudo se deu em 4 etapas metodológicas (Figura 3), sendo que a etapa 1 consistiu na seleção e préprocessamentos das imagens de satélite para os anos 1990 e 2015. Na etapa 2 foram selecionadas as classes de análise com base nos objetivos da pesquisa e resolução dos dados disponíveis. A classificação supervisionada foi executada no software Spring através do método de Máxima Verossimilhança, gerando assim mapas temáticos de uso do solo, cuja validação de precisão e acurácia se deu pela análise da Matriz de Confusão e do Índice Kappa. Já na etapa 3, as imagens classificadas foram inseridas no software Fragstats, onde foram selecionadas as métricas relativas ao nível estrutural de classe, cuja análise se dá pela configuração do conjunto de fragmentos com atributos em comum.

Neste trabalho, além da estrutura ao nível de classe, as métricas também foram escolhidas por sua composição, que contemplam a presença ou ausência de unidades, sua riqueza e a área que ocupam na paisagem. Eles pertencem a categoria de Área e Borda: Área da Classe (CA), Porcentagem de fragmentos da mesma classe na paisagem (PLAND), Área média dos fragmentos (AREA_MN); E também foram selecionadas por sua disposição, que quantificam o arranjo espacial em termos de fragmentação. São as métricas da categoria de Proximidade e Isolamento: Índice de proximidade média (PROX_MN), Distância do vizinho mais próximo (ENN_MN), Número de fragmentos (NP) e Densidade de fragmentos (PD). 
Figura 3 - Fluxograma de atividades conforme metodologia adotada

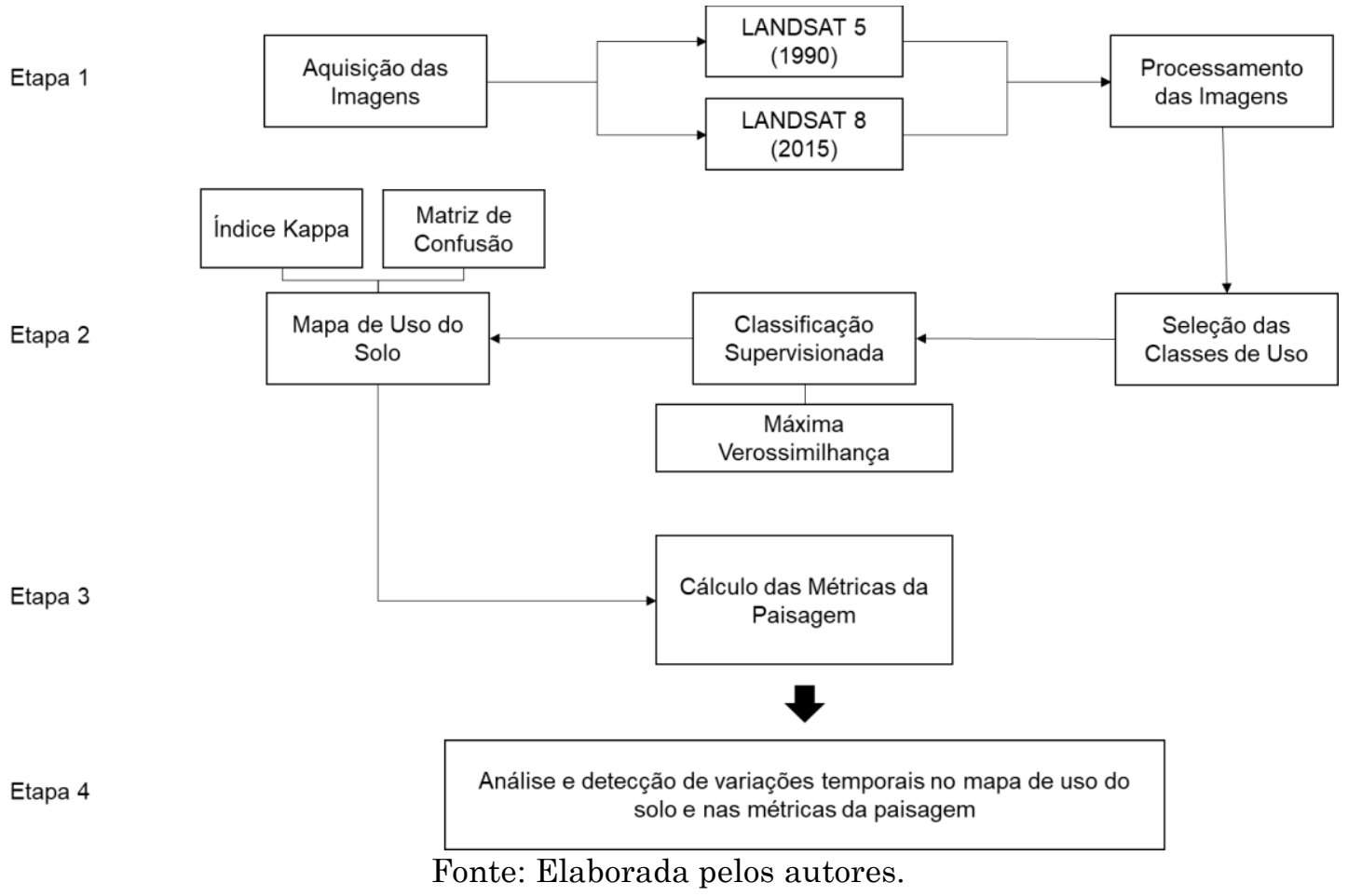

Por último, a etapa 4 é referente a análises das variações temporais quantitativas e espaciais dos fragmentos, comparando com os resultados obtidos nos mapas de uso do solo e que proporcionam a formulação das análises e conclusões desta pesquisa.

\section{Resultados e Discussão}

3.1 Mapas de uso do solo

As análises das mudanças ocorridas na paisagem podem ser conduzidas de diferentes maneiras. Neste estudo, as primeiras observações foram possíveis através dos mapas de uso do solo, gerados após a classificação supervisionada.

Desta maneira, foi possível constatar a expansão de duas classes relacionadas ao crescimento da influência antrópica no intervalo dos 25 anos 
deste estudo. Na figura 4 é possível comparar essas mudanças observando os mapas de uso do solo produzidos para os anos 1990 e 2015.

Figura 4 - Mapas de uso do solo gerados após a classificação supervisionada. A: Uso do solo em 1990; B: Uso do solo em 2015

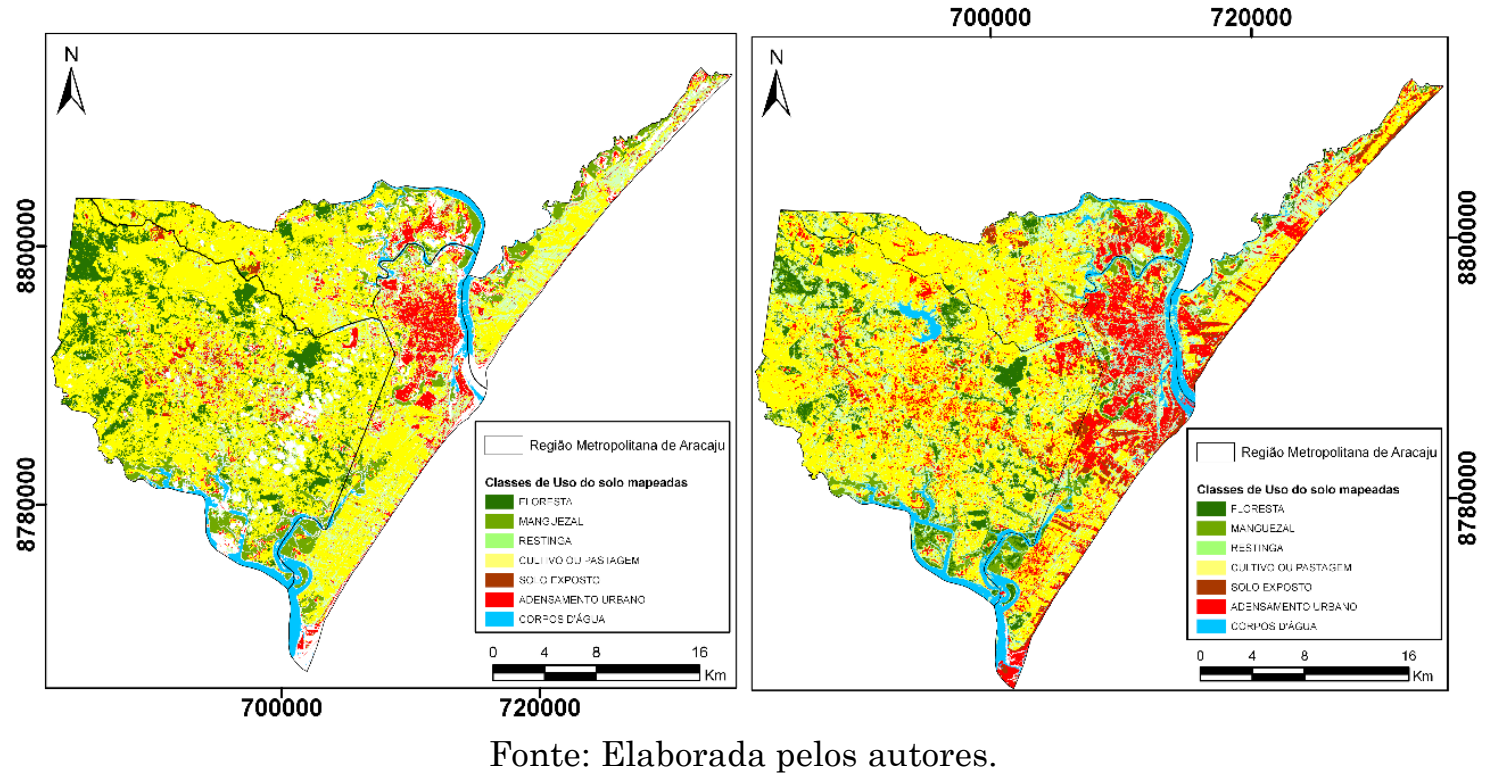

O resultado da análise está representado na Tabela 1, onde constam os valores em hectares (ha) e porcentagens (\%) de cada uma das classes para os anos analisados.

Tabela 1 - Extensão territorial das classes de uso do solo nos anos 1990 e 2015 em hectares e a porcentagem que ocupa na paisagem total

\begin{tabular}{c|cccc}
\multicolumn{1}{c}{ Classes } & $\mathbf{1 9 9 0}(\mathbf{h a})$ & $\mathbf{1 9 9 0}(\boldsymbol{\%})$ & $\mathbf{2 0 1 5}(\mathbf{h a})$ & $\mathbf{2 0 1 5}(\boldsymbol{\%})$ \\
\hline Floresta & $8.568,27$ & 9,91 & $5.676,57$ & 6,57 \\
Mangue & $4.720,59$ & 5,46 & $4.946,67$ & 5,72 \\
Restinga & $10.547,82$ & 12,20 & $15.477,03$ & 17,90 \\
Cultivo elou Pastagem & $43.498,62$ & 50,32 & $38.259,09$ & 44,26 \\
Solo Exposto & $1.183,59$ & 1,37 & $2.669,49$ & 3,09 \\
Adensamento Urbano & $6.315,39$ & 7,31 & $13.177,17$ & 15,24 \\
Corpos D'Água & $3.180,96$ & 3,68 & $4.797,90$ & 5,55 \\
Total: & $\mathbf{7 8 . 0 1 5 , 2 4}$ & $\mathbf{9 0 , 2 4}$ & $\mathbf{8 5 . 0 0 3 , 9 2}$ & $\mathbf{9 8 , 3 3}$
\end{tabular}

Fonte: Elaborada pelos autores. 
Para validar os mapas de uso do solo, foram analisadas as matrizes de confusão geradas após a classificação das imagens, cujos resultados foram, respectivamente, $83 \%$ e 0,79 para o ano de 1990 e $83 \%$ e 0,80 para 2015 estes resultados foram considerados dentro dos parâmetros aceitáveis por Landis e Koch (1977), para utilização, permitindo assim, a continuação da análise dos dados nas etapas seguintes.

\subsection{Análise das métricas}

As métricas sob investigação têm várias faixas de valores e unidades diferentes, assim havia duas opções: analisar uma classe particular e um conjunto de métricas correspondentes, ou analisar uma única métrica de cada vez para todas as classes. A primeira opção foi escolhida para facilitar a discussão acerca das mudanças enfatizando cada classe.

\subsubsection{Floresta}

A área total da classe (CA) e a porcentagem da classe na paisagem (PLAND) indicaram uma progressiva diminuição na classe floresta no intervalo analisado. Na Figura 5 observa-se a comparação entre as manchas dos anos analisados. 
Figura 5 - Comparação das manchas da classe Floresta entre os anos 1990 e 2015

1990

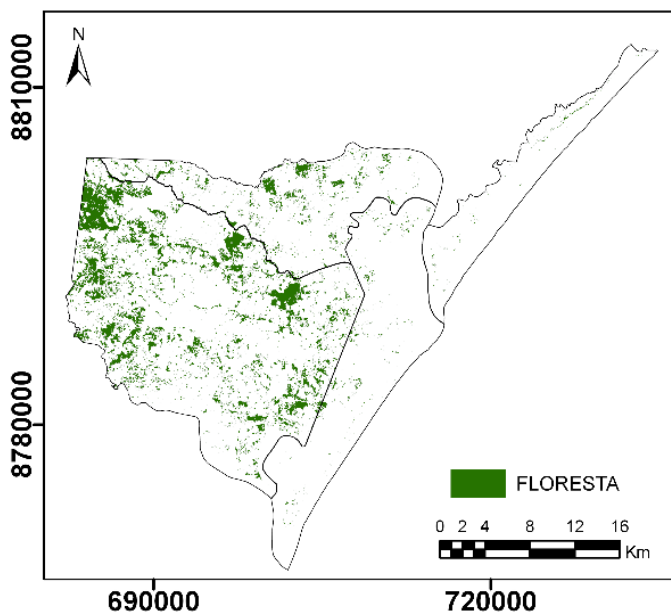

Fonte: Elaborada pelos autores.
2015

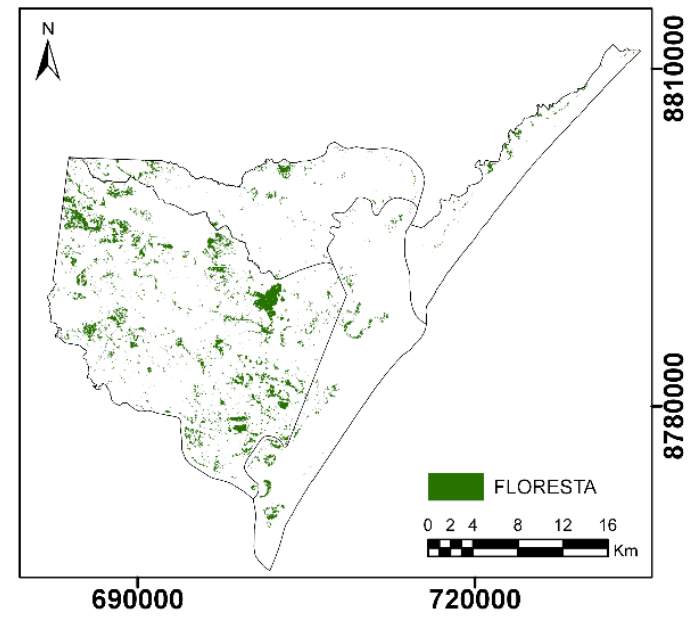

Essa diminuição de 8.568,27 ha (10,98\%), em 1990 para 5.676,57 ha (6,68\%), em 2015 pode ser explicada pelo aumento das áreas de pastagens, o aumento de áreas desmatadas para plantação de outros cultivos e o não cumprimento da legislação ambiental (FERNANDES, 2015).

Acompanhando esta tendência, observou-se uma diminuição do número de fragmentos (NP), que em 1990 totalizava 5.609 fragmentos de Floresta e em 2015 diminuiu para 4.203 fragmentos, assim como a diminuição do tamanho médio dos fragmentos (AREA_MN) demonstrando que além de mais fragmentada, a classe perdeu também parte da área que ocupava.

Para Silva e Souza (2014), a formação de pequenos fragmentos e o retalhamento da paisagem, são consequências geradas a partir da demanda de solos férteis para cultivos. Nesse sentido, a redução no tamanho dos fragmentos suscita também implicações na sua conservação. Essa retirada geralmente é feita em áreas de floresta nativa, formando vários fragmentos na paisagem (GOERL et al., 2011).

Além disso, o tamanho médio dos fragmentos revela que desde o primeiro ano de estudo a classe apresenta alto grau de fragmentação, já que em 1990 o tamanho médio dos fragmentos era 1,52 ha e em 2015 diminuiu 
para 1,35 ha e uma vez que esse índice é calculado em função do número de fragmentos e da área total ocupada pela classe. Segundo Mcgarigal, Tagil e Cushman (2009), paisagens que apresentam menores valores para tamanho médio do fragmento devem ser consideradas como mais fragmentadas.

Ao adicionar à análise a métrica de densidade de manchas (PD), é possível traçar um delineamento da fragmentação desta classe, pois ela fornece o número de manchas por uma unidade de área. Nesta classe, obtevese, em 1990, 7,19 fragmentos a cada 100 hectares, havendo diminuição para 4,94 fragmentos/100 ha em 2015. O principal problema deste padrão é que quanto mais área florestada estiver contida em pequenos fragmentos, mais intensamente estaria sujeita ao efeito de borda (RODRIGUES, 1993).

Para avaliar o isolamento entre os fragmentos foi utilizado o índice ENN_MN, que calcula a distância média do fragmento mais próximo, para o qual foram obtidos os valores 107,34 para o ano de 1990 e 108,72, em 2015. Usando este índice foi possível verificar que esta classe apresenta alto grau de isolamento, uma vez que, segundo Almeida (2008), distâncias médias entre fragmentos menores que 60 metros são classificados como de baixo isolamento. Já os resultados de Calegari et al. (2010), em regiões do Rio Grande do Sul, demonstraram que foram encontradas distâncias médias entre fragmentos de $244,50 \mathrm{~m}$ e $82,22 \mathrm{~m}$, respectivamente, o que demonstra serem áreas com o grau de isolamento variando de muito alto a médio.

De acordo com os dados apresentados é possível inferir que na área de estudo não existem grandes áreas de remanescentes de vegetação natural a serem conservadas, e sim um considerável número de pequenos fragmentos de vegetação inseridos em uma matriz de uso antrópico, principalmente áreas agropastoris.

\subsubsection{Mangue}

A vegetação que compõe a classe Mangue também faz parte do domínio da Mata Atlântica que ocupam as margens dos rios, as ilhas estuarinas e as 
planícies fluviomarinhas e juntamente com os apicuns, encontram-se presentes em todos os estuários de Sergipe (PRATA et al., 2013). As mudanças verificadas (Figura 6), com base nos resultados das métricas possibilitaram comparar que a área total da classe em 1990 foi de 4.720,59 ha representando 6,05\% da área total da paisagem para aquele ano (78.015,24 hectares), já em 2015 a área ocupada pela classe foi 4.946,67 hectares, o que representou $5,82 \%$ da área total ocupada por todas as classes em 2015 (85.003,92 ha).

Figura 6 - Comparação das manchas da classe Mangue entre os anos 1990 e 2015 1990

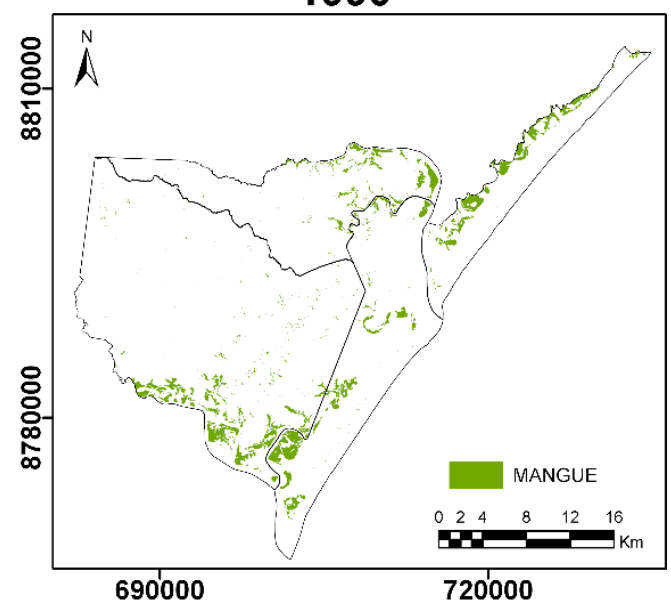

2015

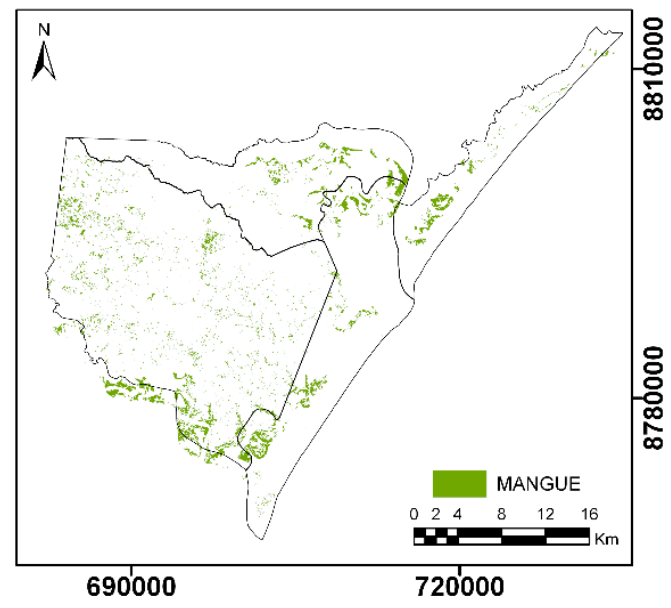

Fonte: Elaborada pelos autores.

Em relação às outras classes desta pesquisa, a classe Mangue foi a que apresentou resultados mais discrepantes. Apesar da área ocupada por esta classe apresentar um pequeno aumento (226,08 ha), os valores das outras métricas aumentaram consideravelmente. O número de fragmentos aumentou de 1.418 fragmentos, em 1990 para 5.341 em 2015. O tamanho médio dos fragmentos dessa classe (AREA_MN) diminuiu de 3,32 ha, em 1990 para 0,92 ha, em 2015. E a densidade de fragmentos (PD) aumentou de 1,68 fragmentos/100 ha, em 1990 para 6,26 fragmentos/100 ha, em 2015.

Analisando essas métricas conjuntamente, ao constatar o aumento de 3.923 fragmentos e uma vez que se observou a tendência de redução do tamanho médio das áreas (AREA_MN) da classe em 72,28 \%, além do aumento de fragmentos a cada 100 hectares. Assim como Fernandes (2015) 
constatou uma maior degradação ao analisar a redução de tamanho dos fragmentos em seu estudo, o resultado desta classe obtido nesta analise revelam que esta classe sofreu fragmentação intensa.

Os valores obtidos para as métricas que medem o grau de isolamento entre os fragmentos da classe Mangue também foram significativos. Para Metzger (1999), o isolamento dos fragmentos promove uma influência negativa na riqueza de espécies. Uma vez que os valores de índice de proximidade médio (PROX_MN) para 1990 e 2015 foram, respectivamente, 24,33 e 11,12, este índice é fortemente influenciado pela redução em área das classes (CA) e pela proximidade entre remanescentes de mesma classe na paisagem (FERNANDES, 2015).

A distância média do fragmento mais próximo (ENN_MN) para a classe apresentou tendência de redução durante o período estudado, que passou de 159,63 em 1990 para 101,89 em 2015, consequência do aumento do número de pequenos fragmentos, o que faz com que os fragmentos pequenos fiquem mais próximos. Borges et al. (2010) mencionaram que esta métrica quantifica a configuração da paisagem e está baseada na distância borda-a-borda.

\subsubsection{Restinga}

A classe Restinga é representada pela formação fitogeográfica da restinga que está assentada sobre solos arenosos, ocorrendo em todo o litoral, podendo atingir até $10 \mathrm{~km}$ de largura em alguns municípios do litoral sergipano e abrangem formações de dunas fixas ou móveis (PRATA et al., 2013).

Os resultados obtidos para a área da classe (CA) e da porcentagem da classe na paisagem (PLAND) demonstram que houve um aumento, pois em 1990 a área ocupada era de $10.547,82$ ha $(13,52 \%)$ e em 2015 passou para $15.477,03$ ha $(18,21 \%)$. No entanto, a partir de observações, infere-se que, por limitações da resolução das imagens, algumas manchas tenham sido confundidas com áreas de floresta degradada ou em processo de regeneração, 
uma vez que estão em áreas antes ocupadas pela classe floresta e não foram encontradas referencias na literatura que identificassem a ocorrência da restinga nessas áreas. Na Figura 7 é possível observar as mudanças da classe.

Figura 7 - Comparação das manchas da classe Restinga entre os anos 1990 e 2015 1990
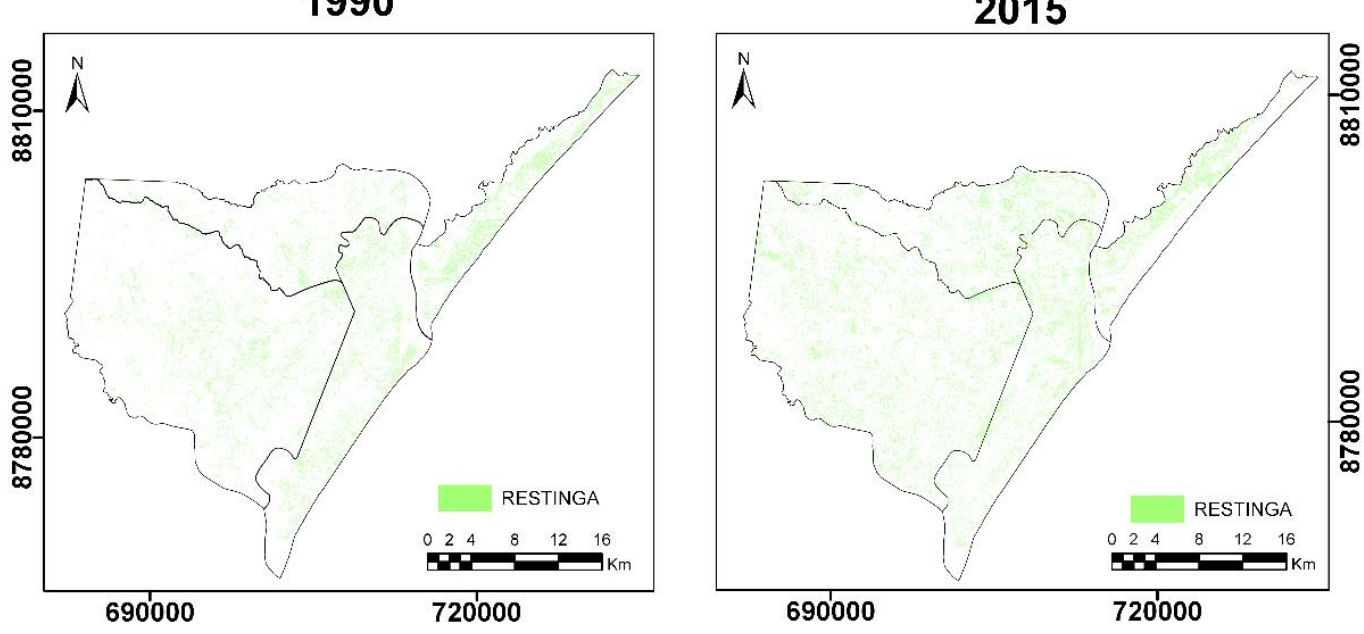

Fonte: Elaborada pelos autores.

Para a análise do número de fragmentos (NP) da classe Restinga, em 1990 foram detectados 12.746 fragmentos e em 2015 foram contabilizados 19.466 fragmentos. Assim como o número de fragmentos, a densidade de fragmentos por unidade de área também aumentou, pois foram identificados em 1990, 16,34 fragmentos/100 hectares e em 2015 esse valor aumentou para 22,90 fragmentos a cada 100 hectares.

O tamanho médio dos fragmentos (AREA_MN) é um importante indicador da fragmentação da classe estudada, e diversos trabalhos apontam que fragmentos pequenos (menores que $5 \mathrm{ha}$ ) indicam alto grau de fragmentação (SOUZA et al., 2014; SAITO et al., 2016). Assim, esse índice teve pouca variação de valores, pois em 1990 o tamanho médio era de 0,82 ha e teve uma pequena redução para 0,79 ha em 2015 .

O índice de proximidade média (PROX_MN) sofreu um aumento de 29,89 em 1990 para 48,47 em 2015. Ou seja, os fragmentos desta classe tornaram-se mais distantes entre si, o que, segundo Ribeiro et al. (2009) apontam como um fator limitante para o deslocamento entre espécies. O outro fator que mede o grau de isolamento entre fragmentos é a distância média do 
fragmento mais próximo (ENN_MN), que diminuiu de 85,70 para 74,08. Esse índice tem grande importância na manutenção da biodiversidade, pois quanto menor a distância entre dois fragmentos, maior a taxa de recolonização pela imigração de indivíduos de outras populações e também maior mobilidade de dispersores e polinizadores (BARROS, 2006).

\subsubsection{Cultivo e/ou Pastagem}

A classe Cultivo e/ou Pastagem pode ser definida por áreas de uso destinado à agricultura e pecuária. No entanto, é importante salientar que não foi possível diferenciar as áreas dessas duas atividades devido à resolução das imagens utilizadas que não permitiram tal definição com clareza. Assim, foi feito um esforço com apoio na literatura, para definir as principais características que compõem essa classe.

Como parte dos cultivos, um destaque especial é atribuído aos coqueirais, que se expandem, principalmente, sobre os solos da planície litorânea e tabuleiros onde se inserem os municípios da Região Metropolitana de Aracaju (ARAÚJO, 2012). O coco-da-Baía (Cocus nucífera) teve sua importância comercial, industrial e artesanal reconhecida por Troppmair (1971), como um dos produtos mais importantes do Estado, exportando grande parte da produção para o mercado nacional. Outros cultivos que tem importância econômica na área de estudo são: a mandioca e a laranja. Os demais cultivos são destinados à agricultura de subsistência (IBGE, 2010).

As pastagens que compõem a área de estudo são destinadas à pecuária, majoritariamente, a extensiva, onde o gado é criado solto, utilizando as áreas das vertentes dos tabuleiros costeiros (ALVES, 2010). A pastagem representa um dos principais tipos de recobrimento, em relação às áreas de cultivos. No entanto, dentre os municípios desta pesquisa, Barra dos Coqueiros destinou maior parte desta classe aos cultivos e Nossa Senhora do Socorro, sobressai as áreas de Pastagem. 
A destinação das terras para a pecuária modifica o meio. Desde o momento de implantação da infraestrutura agrícola, com a retirada da vegetação nativa, até a compactação do solo e aumento da erosão devido ao superpastoreio (JESUS et al., 2015). Desta maneira, Fontes (1997), que realizou a caracterização ambiental de uma bacia hidrográfica do litoral sergipano, concluiu que as formas de utilização das terras, associadas às práticas agrícolas, tradicionais e modernas, desempenham importante papel na conservação e/ou degradação dos solos, numa sequência decrescente de intensidade-mata-pastagem-culturas de ciclos longos e curtos.

Assim como nos mapas de uso do solo, após o cálculo das métricas a classe Cultivo e/ou Pastagem apresentou a maior área da classe (CA) e porcentagem da classe na paisagem (PLAND), representando assim a matriz da paisagem da área de estudo. A classe ocupou em 1990, uma área de $43.498,62$ ha $(55,76 \%)$ e em 2015 , teve uma redução para $38.259,09$ ha (45,01\%). As mudanças ocorridas são observadas na Figura 8.

Figura 8 - Comparação das manchas da classe Cultivo e /ou Pastagem entre os anos 1990 e 2015
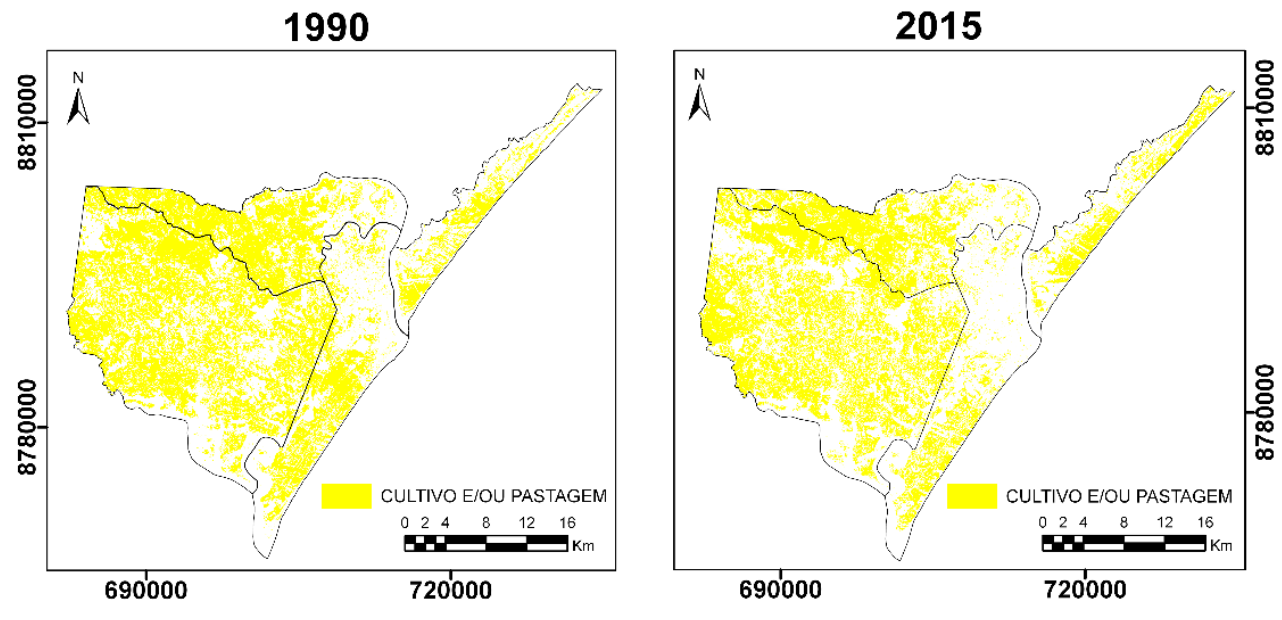

Fonte: Elaborada pelos autores.

A redução desta área pode estar relacionada ao aumento de outras classes, como por exemplo, a classe Adensamento Urbano, assim como afirma Wanderley (1998), sobre o aumento dos problemas fitossanitários e do 
crescimento da especulação imobiliária, que muito contribui para a redução dos coqueirais, o que causam prejuízos para a paisagem.

Um dos índices que podem atestar o aumento do grau de fragmentação desta classe é o número que fragmentos (NP), pois, apesar da diminuição da área, foi possível atestar que, em 1990, a classe totalizava 4.189 fragmentos e em 2015 aumentou para 5.793 fragmentos. Como afirmaram Cabacinha et al. (2010), o aumento do número de fragmentos implica em fragmentos menores de uma determinada classe, o que define seu grau de fragmentação.

Um dos índices que podem atestar o aumento do grau de fragmentação desta classe é o número que fragmentos (NP), pois, apesar da diminuição da área, foi possível atestar que, em 1990, a classe totalizava 4.189 fragmentos e em 2015 aumentou para 5.793 fragmentos. Como afirmaram Cabacinha et al. (2010), o aumento do número de fragmentos implica em fragmentos menores de uma determinada classe, o que define seu grau de fragmentação.

Somado ao número de fragmentos, outro índice que legitima o aumento da fragmentação é o tamanho médio dos fragmentos (AREA_MN), que teve uma redução de 10,38 ha em 1990 para fragmentos com 6,60 ha em 2015 . Apesar de menores, a densidade de fragmentos por unidade de área aumentou, pois em 1990 era possível encontrar 5,37 fragmentos/100 ha, já em 2015 os fragmentos estavam mais próximos, com 6,82 fragmentos/100 ha.

Continuando a análise das métricas de isolamento da paisagem, tanto o índice médio de proximidade entre fragmentos de uma classe (PROX_MN), como a distância média até o fragmento vizinho mais próximo (ENN_MN), diminuíram. Os valores de PROX_MN para 1990 e 2015 foram, respectivamente, $27.973,27$ e $16.976,57$ revelando que os fragmentos desta classe estão mais unidos entre si. Para reafirmar essa colocação os valores de ENN_MN para 1990 e 2015 foram, respectivamente, 79,63 e 77,52, demonstrando que na área de estudo, ainda que a classe tenha diminuído, cedendo área para outras, o grau de fragmentação aumentou. 


\subsubsection{Solo Exposto}

Segundo Araújo (2012), esta classe refere-se a pequenas áreas de afloramentos rochosos sem a interferência antrópica, disseminados descontinuamente, cuja superfície está diretamente exposta aos agentes intempéricos, face a ausência de um manto vegetal regularizador desse processo.

Segundo os resultados das métricas, em 1990 a área total ocupada por esta classe (CA) era 1.183,59 hectares, o que representava uma porcentagem na paisagem (PLAND) de 1,52\%. Em 2015, a área da classe aumentou mais que o dobro, apresentando uma área de 2.669,49 hectares e 3,14\% da área total da paisagem. Na Figura 9 pode-se comparar as mudanças na configuração das manchas entre os anos do estudo.

Figura 9 - Comparação das manchas da classe Solo Exposto entre os anos 1990 e 2015
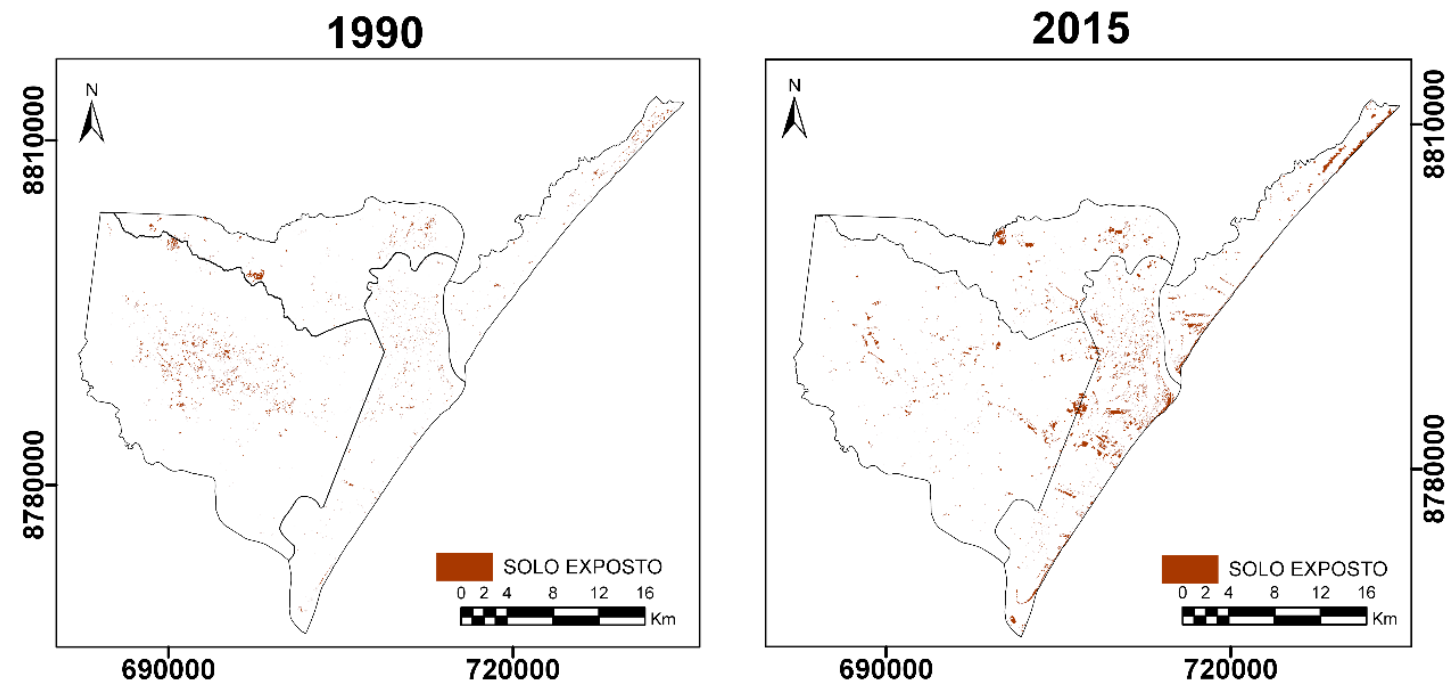

Fonte: Elaborada pelos autores.

O número de fragmentos (NP), diminuiu de 3.727 fragmento em 1990 para 3.612 fragmentos em 2015. O aumento da área da classe somado à diminuição do número de fragmentos sugere que houve uma união entre fragmentos desta classe e, consequentemente tornando-os maiores. Como é possível constatar pelo tamanho médio dos fragmentos (AREA_MN), os quais 
em 1990 possuíam tamanhos médios de 0,31 ha e no último ano analisado, 2015 apresentou fragmentos de 0,73 ha.

A densidade de fragmentos (PD) da classe apresentou pouca variação, contabilizando, em 1990, 4,78 fragmentos/100 ha e em 2015 teve uma redução desprezível, visto que em 2015 esse valor passou a ser 4,25 fragmentos a cada 100 ha. O índice de proximidade médio (PROX_MN) aumentou, uma vez que em 1990 a distância média entre os fragmentos era de 1,75 e em 2015 a distância passou a ser 6,02. Já a distância média até o fragmento mais próximo (ENN_MN) sofreu uma redução de 130,78 em 1990 para 123,25 em 2015, o que indica que apesar de maiores, as manchas dessa classe estão mais dispersas na paisagem em questão neste estudo.

\subsubsection{Adensamento urbano}

Esta classe é caracterizada pelas áreas de ocupação antrópica tradicional, uma vez que os municípios que compõem a Região Metropolitana de Aracaju são considerados o núcleo mais urbanizado do Estado. Sua formação se remete ao boom de crescimento populacional da capital, que veio com a chegada de indústrias a partir dos anos 60. A industrialização passou a atrair grande número de migrantes de municípios do interior e também de outros estados (FONTES DE SOUZA, 2009).

Com a expansão demográfica, a intensa urbanização de Aracaju e a especulação imobiliária, os lotes que já eram considerados caros sofreram uma elevação de preços. Como consequência, a cidade foi se expandindo e a população que não tinha poder aquisitivo para adquirir terrenos em áreas mais nobres foi buscando áreas com valores mais acessíveis nas periferias e nos municípios vizinhos (FEITOSA, 2006).

O processo de metropolização de Aracaju seguiu o modelo de desenvolvimento proposto pela Superintendência do Desenvolvimento do Nordeste (Sudene), que fomentava a industrialização de regiões periféricas na Região Nordeste (Souza, 2009). Com a consolidação da industrialização os 
fluxos migratórios para Aracaju e regiões adjacentes foram transformando e dinamizando o espaço. Ao mesmo tempo, a cidade foi sendo empurrada para os municípios vizinhos através da implantação de conjuntos habitacionais e loteamentos, aumentando a complexidade da dinâmica urbana (FRANÇA, 2005).

Assim como afirma a literatura, após o cálculo das métricas foi possível avaliar quantitativamente o crescimento da classe Adensamento Urbano. A área total da classe (CA), que em 1990 abrangia uma área de 6.315,39 hectares, o que representa uma porcentagem de classe (PLAND) de 8,10\% e em 2015 totalizou 13.177,17 ha e porcentagem de classe de 15,50\%, sendo a diferença mais que o dobro do primeiro ano analisado. Na Figura 10 onde está representada a classe de adensamento urbano é possível observar o "espalhamento" da classe para além dos limites de Aracaju, aumentando o processo de conurbação (unificação da mancha urbana em consequência do crescimento populacional), entre os municípios componentes da RMA. Sendo que, o número de fragmentos (NP) aumentou de 5.127 fragmentos em 1990 para 7.520 fragmentos em 2015, sugerindo, conforme o aumento da área da classe, o surgimento de novos fragmentos. Além disso, o tamanho médio dos fragmentos (AREA_MN) dessa classe aumentou de 1,23 ha em 1990, para 1,75 ha em 2015, o que pode ser interpretado como a união de fragmentos a outros já existentes. 
Figura 10 - Comparação das manchas da classe Adensamento Urbano entre os anos 1990 e 2015

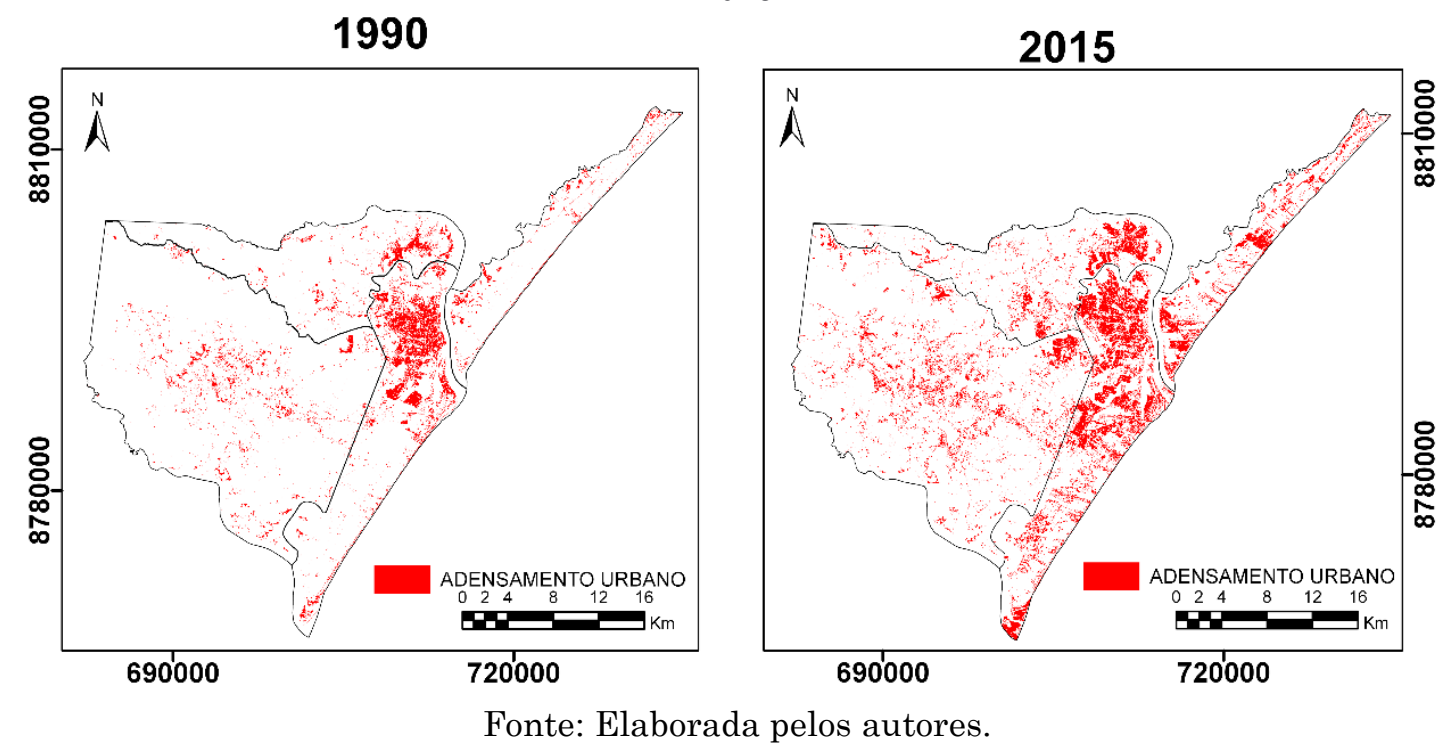

A densidade de fragmentos (PD) apresentou para o ano de 1990, 6,57 fragmentos a cada 100 hectares, já em 2015 ocorreu um aumento para 8,85 fragmentos/100 ha, corroborando com o aumento do número de fragmentos desta classe ter aumentado.

Quanto às métricas relacionadas ao isolamento, índice de proximidade médio (PROX_MN) cujos valores para 1990 e 2015 foram, respectivamente, 120,84 e 222,38, revelando um afastamento entre as manchas. A distância média até o vizinho mais próximo diminuiu de 106,05 em 1990 para 89,11 em 2015.

\subsubsection{Corpos D’água}

A classe Corpos D’Água abrangeu os cursos de rios, lagos, represas e quaisquer outros recursos hídricos que puderam ser detectados pelo método de classificação utilizado nessa pesquisa. Essa classe foi escolhida por haver apresentado um aumento significativo para a área de estudo no intervalo analisado. Os resultados dessa classe foram influenciados pela construção da represa do Poxim-Açú, desta maneira, foram alterados os valores de área total da classe e da porcentagem da classe na paisagem total. Tais mudanças podem ser observadas na Figura 11. 
Figura 11 - Comparação das manchas da classe Corpos D’Água entre os anos 1990 e 2015

1990

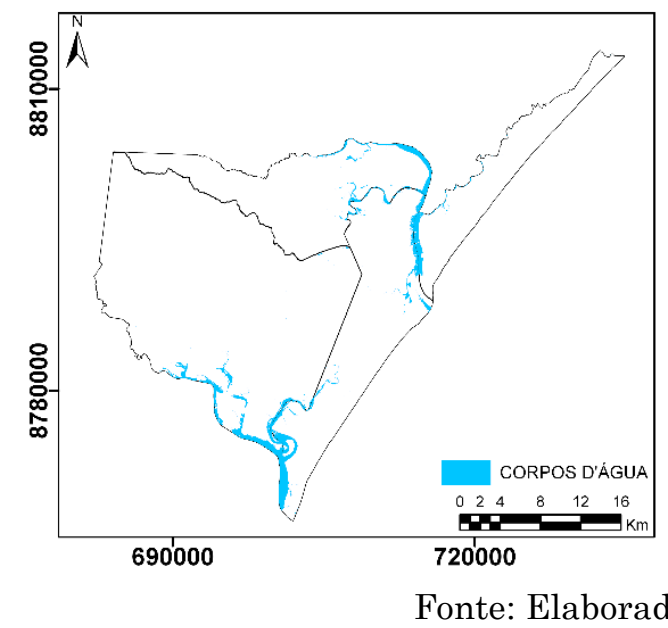

2015

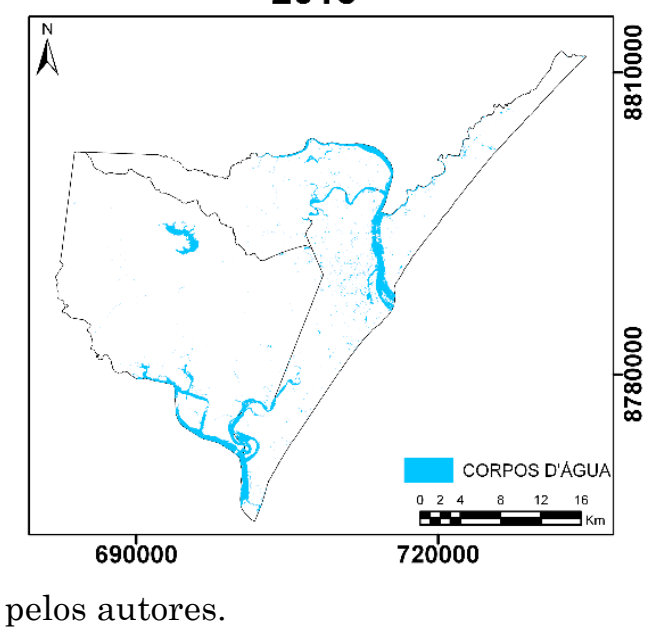

Sendo assim, os resultados obtidos para a área da classe (CA) variaram de 3.180,96 ha em 1990 para 4.797,90 ha em 2015. Em porcentagem, a classe representa para os anos 1990 e 2015, 4,08\% e 5,64\%, respectivamente. O número de fragmentos (NP) aumentou de 408 em 1990, para 2.468 fragmentos detectados na imagem classificada para o ano de 2015.

A densidade de fragmentos (PD) também apresentou aumento significativo, uma vez que em 1990 eram encontrados 0,52 fragmentos a cada 100 ha e em 2015 foram encontrados 2,90 fragmentos/100 ha. Para o tamanho médio dos fragmentos (AREA_MN), obteve-se valores de fragmento de 7,79 ha para o ano de 1990 e 1,94 ha para o ano de 2015. Assim foi possível perceber que ocorreu uma redução no tamanho dos fragmentos, ocasionando num maior grau de fragmentação desta classe.

Os índices de proximidade médio (PROX_MN) e distância média até o vizinho mais próximo (ENN_MN) analisam que o grau de isolamento desta classe aumentou, pois, o índice de proximidade resultante em 1990 foi de 239,77 e de 202,75 em 2015 e, de acordo esses valores, à medida que esse índice diminui, as manchas vão se distanciando entre si. Já os valores de distância até o vizinho mais próximo foram, respectivamente, 192,04 e 146,88.

A partir das análises foi possível observar que, desde 1990, a área de estudo vem passando por transformações em sua paisagem e as áreas de 
vegetação natural - Floresta, Mangue e Restinga - sendo sobrepostas por classes relacionadas ao uso antrópico (Quadro 1).

Quadro 1 - Síntese das classes analisadas na área de estudo para os anos 1990 e 2015

\begin{tabular}{|c|c|c|c|}
\hline \multirow{2}{*}{ Classes } & \multicolumn{2}{|c|}{ Área ocupada (\%) } & \multirow{2}{*}{ Sintese } \\
\hline & 1990 & 2015 & \\
\hline $\begin{array}{l}\text { Relacionadas } \\
\text { a áreas de } \\
\text { vegetação } \\
\text { natural }\end{array}$ & $\begin{array}{c}\text { Floresta }-10,98 \% \\
\text { Mangue }-6,05 \% \\
\text { Restinga }-13,52 \%\end{array}$ & $\begin{array}{c}\text { Floresta }-6,68 \% \\
\text { Mangue }-5,82 \% \\
\text { Restinga }-18,21 \%\end{array}$ & $\begin{array}{l}\text { Diminuição das } \\
\text { áreas de vegetação } \\
\text { nativa; Confusão } \\
\text { da classificação } \\
\text { das áreas de } \\
\text { Restinga com } \\
\text { áreas de Floresta } \\
\text { degradada, } \\
\text { justificando o } \\
\text { aumento. }\end{array}$ \\
\hline $\begin{array}{l}\text { Relacionadas } \\
\text { ao uso } \\
\text { antrópico }\end{array}$ & $\begin{array}{c}\text { Cultivo e/ou } \\
\text { Pastagem - 55,76\% } \\
\text { Solo Exposto - 1,52\% } \\
\text { Adensamento } \\
\text { urbano - 8,10\% }\end{array}$ & $\begin{array}{c}\text { Cultivo e/ou } \\
\text { Pastagem - 45,01\% } \\
\text { Solo Exposto - 3,14\% } \\
\text { Adensamento } \\
\text { urbano }-15,50 \%\end{array}$ & $\begin{array}{l}\text { Diminuição da } \\
\text { área da Matriz } \\
\text { (Cultivo e/ou } \\
\text { Pastagem); } \\
\text { Aumento das } \\
\text { áreas das classes } \\
\text { relacionadas às } \\
\text { atividades } \\
\text { antrópicas. }\end{array}$ \\
\hline
\end{tabular}

Fonte: Elaborado pelo autores.

\section{Conclusões e Recomendações}

A partir da metodologia proposta foi possível constatar as mudanças temporais na paisagem da Região Metropolitana de Aracaju identificando-as e quantificando-as a partir da aplicação das métricas da paisagem, apesar do nível de detalhamento ser reduzido em função da escala trabalhada ser pequena.

Assim, foi possível traçar uma tendência das classes que estão em maior grau de fragmentação, fazendo ser possível identificar e promover ações de prevenção, controle e recuperação de áreas degradadas destacando desta maneira o grau de fragmentação da paisagem e suas implicações no planejamento e gestão espacial.

A redução das coberturas vegetais nativas Floresta e Mangue e a redução da classe Cultivo e/ou Pastagem, que foi identificada como a matriz 
da paisagem de estudo em detrimento do aumento da classe Adensamento Urbano, indicam a necessidade de políticas públicas voltadas à restauração das áreas de vegetação nativa e a implantação de sistemas compatíveis para o desenvolvimento sustentável e econômico da Região Metropolitana de Aracaju.

Outra contribuição desta pesquisa deu-se no sentido de compreender que se faz necessária a observação das mudanças ocorridas na paisagem ao longo do tempo, pois a partir delas é possível entender os processos - naturais ou antrópicos - que as influenciam e podem nortear prognósticos de tendências futuras.

Uma das limitações deste trabalho neste sentido foi justamente a quantidade de imagens de satélites temporais disponíveis. Porém, destaca-se que, mesmo assim, foi possível quantificar 25 anos de mudanças. Caso novas imagens forem adquiridas elas podem contribuir para o estudo onde a metodologia empregada permanece a mesma. Destaca-se também que esta pesquisa demonstrou resultados satisfatórios utilizando dados gratuitos, o que facilita a execução de mais estudos voltados ao planejamento da paisagem.

Por fim, do ponto de vista metodológico deste estudo, existem algumas limitações, como as imagens de média resolução que limitam à uma escala específica por dois motivos: a escassez de imagens com pouco recobrimento de nuvens na área do litoral e também a identificação das classes de uso do solo no momento da classificação, assim como as métricas da paisagem a serem aplicadas.

Para o estudo e monitoramento da fragmentação da paisagem recomenda-se dar continuidade em projetos que envolvam um maior número de imagens de satélites, com o propósito de acompanhar a evolução e manter desta forma um banco de dados atualizado. Novas informações, além de aumentar as amostras temporais, contribuem diretamente no diagnóstico e deteç̧ão de áreas de risco bem como de preservação ambiental. 


\section{Agradecimentos}

Os autores gostariam de agradecer ao suporte do Programa de PósGraduação em Ciências Geodésicas e Tecnologias da Geoinformação da UFPE, ao projeto PQ/nível 2/CNPq nº do Proc. 310452/2018-0 e a CAPES pela concessão da bolsa PNPD nº do Proc. 88887.319598/2019-00.

\section{Contribuição dos autores}

Definição da problemática (G. B. Valenzuela e R. M. Gonçalves), revisão de literatura e definição dos procedimentos metodológicos (G. B. Valenzuela, R. M. Gonçalves e P. H. G. O. Sousa), aquisição e processamento dos dados (G. B. Valenzuela), organização e escrita do texto (G. B. Valenzuela, R. M. Gonçalves, P. H. G. O. Sousa e H. A. A. Queiroz), produção e organização dos mapas (G. B. Valenzuela e H. A. A. Queiroz).

\section{Referências}

ALMEIDA, C. G. Análise espacial dos fragmentos florestais na área do Parque Nacional dos Campos Gerais, Paraná. Dissertação de Mestrado. Universidade Estadual de Ponta Grossa, Programa de PósGraduação em Geografia, Ponta Grossa, 2008. 72p.

ALVES, N. M. S. Análise geoambiental e socioeconômica dos municípios costeiros do litoral norte do estado de Sergipe Diagnóstico como subsídio ao ordenamento e gestão do território. Tese de doutoramento. Universidade Federal de Sergipe. Programa de Pós-Graduação em Geografia, São Cristóvão, 2010. 348p.

ARAÚJO, H. M. D. Cobertura vegetal, uso do solo e ocupação da terra na bacia costeira do rio Sergipe. 2012. Disponível em: $<$ http://observatoriogeograficoamericalatina.org.mx/egal12/Procesosam bientales/Impactoambiental/19.pdf>. Acesso em: 29 maio 2016.

AZEVEDO, D. G.; GOMES, R. L.; DE MORAES, M. E. B. Estudos da fragmentação da paisagem na definição de áreas prioritárias para a recuperação ambiental da bacia hidrográfica do Rio Buranhém. Boletim de Geografia, vol. 34, n. 2, 2016. pp. 127. 
BARROS, F. A. Efeito de borda em fragmentos de Floresta Montana, Nova Friburgo - RJ. Dissertação de Mestrado. Universidade Federal Fluminense, Niterói. 2006. 112p.

BITTENCOURT, A. C. S. P. MARTIN, L.; DOMINGUEZ, J. M. L.; FLEXOR, J. M.; FERREIRA, Y. A. Evolução Paleogeográfica Quaternária da Costa do Estado de Sergipe e da Costa Sul do Estado de Alagoas. Revista Brasileira de Geociências, vol. 13, n. 2, 1983. pp. 93-97.

BORGES, J.; CARVALHO, G.; MOURA, A. C. M.; NASCIMENTO, J. Estudo da conformação da paisagem de Sabará-MG para compreensão das métricas do fragstats em padrões de uso do solo. Congresso Brasileiro de Cartografia, Sergipe, 2010. pp. 1473-1481.

BRASIL. Ministério das Minas e Energia. Projeto RADAMBRASIL: folha SC.24/25 Aracaju/Recife: geologia, geomorfologia, pedologia, vegetação, uso potencial da terra. Rio de Janeiro, 1983. 851 p. (Levantamento de Recursos Naturais,30). 2006.

CABACINHA, C. D.; CASTRO, S.S.; GONÇALVES, D. A. Análise da estrutura da paisagem da alta bacia do Rio Araguaia na savana brasileira. Revista Floresta, Curitiba, vol. 40, n. 4, 2010. pp. 675-690.

CALEGARI, L.; MARTINS, S. V.; GLERIANI, J. M.; SILVA, E.; BUSATO, L. C. Análise da dinâmica de fragmentos florestais no município de Carandaí, MG, para fins de restauração florestal. Revista Árvore, Viçosa, vol. 34, n. 5, p. 871-880, 2010.

CAMELO, A. P. S.; SANCHES, K. L. A Importância da Legislação Ambiental para Manutenção de Áreas Protegidas em Bacias Urbanas. Enciclopédia Biosfera, vol.13 n.23, 2016. pp. 1-15, 2016.

COELHO, A. S.; MARENZI, R. C.; IZA, O. B.; SOUZA, V. A. C.; LONGARETE, C. Análise da estrutura espacial e funcional da paisagem aplicada ao planejamento da conservação da natureza no município de Itajaí, Santa Catarina, Brasil. Geosul. vol. 33, n. 66, 2018. pp. 304-327.

DE ANDRÉS, M.; BARRAGÁN, J. M.; SCHERER, M. Urban centres and coastal zone definition: Which area should we manage?. Land Use Policy, vol. 71, 2018. pp.121-128.

DESMET, P G. Using landscape fragmentation thresholds to determine ecological process targets in systematic conservation plans. Biological Conservation, vol. 221, 2018. pp. 257-260.

EMBRAPA, Empresa Brasileira de Pesquisa Agropecuária. Delimitação da área de atuação da Embrapa Tabuleiros Costeiros. OS N 09 / 2014. Relatório Final. Aracaju-SE. 2014.

FEITOSA, Cid Olival. Reflexões acerca do urbano em Sergipe. Revista Econômica do Nordeste, vol. 37, n. 3. 2006. pp. 339-355.

FERNANDES, M. Dinâmica do uso e cobertura da terra e aptidão para o manejo florestal na região semiárida do Estado de Sergipe SE. 2015. 113f. Dissertação de Mestrado. Universidade de Brasília, Programa de Pós-Graduação em Ciências Florestais, Brasília, 2015. 98p. 
FERNANDES, M.; FERNANDES, M.; ALMEIDA, A.; GONZAGA, M. I. S.; GONÇALVES, F. Ecologia da Paisagem de uma Bacia Hidrográfica dos Tabuleiros Costeiros do Brasil. Floresta e Ambiente, vol. 24, 2017.

FONTES DE SOUZA, B. C. M. Desenvolvimento regional e gestão metropolitana: reflexões a partir da política habitacional na região metropolitana de Aracajú. Dissertação de Mestrado. Universidade Federal de Sergipe. Mestrado Profissional em Desenvolvimento Regional e Gestão de Empreendimentos Locais. São Cristóvão, 2009. 140p.

FONTES, A. L. Caracterização geoambiental da bacia do rio Japaratuba/SE. Tese de doutorado, Rio Claro, IGCE/UNESP, 1997. $298 \mathrm{p}$.

FORMAN, R. T.; GORDON, M. Landscape Ecology. Ed. John Willey, Nova Iorque, 619 p., 1986.

FRANÇA, V.L. A. O Direito à Cidade de Aracaju In: FRANÇA, V. L. A.(Org.); FALCON, M. L. O. (Org.). Aracaju: 150 anos de vida urbana. Aracaju: PMA/SEPLAN, 2005.

GOERL, R. F.; SIEFERT, C. A. C.; SCULTZ, G. B.; SANTOS, C. S.; SANTOS, I. Elaboração e Aplicação de Índices de Fragmentação e Conectividade da Paisagem para Análise de Bacias Hidrográficas. Revista Brasileira de Geografia Física, vol. 5, n. 1, 2011. pp.1000-1012.

IBGE, Instituto Brasileiro de Geografia e Estatística. Brasil em Síntese. 2017. Site < https://cidades.ibge.gov.br/>acessado em Abril de 2018.

IBGE, Instituto Brasileiro de Geografia e Estatística. Censo Demográfico. 2010.

Site

http://www.censo2010.ibge.gov.br/primeiros_dados_divulgados/index.p hp? uf=28>, acessado em Novembro de 2016.

INMET, Instituto Nacional de Meteorologia. Site $<$ http://www.inmet.gov.br/portal/index.php?r=estacoes/estacoesConven cionais>, acessado em Outubro de 2016.

JESUS, E. N.; FERREIRA, R. A.; ARAGÃO, A. G.; SANTOS, T. I. S.; ROCHA, S. L. Estrutura dos Fragmentos Florestais da Bacia Hidrográfica do Rio Poxim-SE, Como Subsídio à Restauração Ecológica. Revista Árvore, Viçosa, vol. 39, n. 3, 2015. pp. 467-474.

KUMAR, M.; DENIS, D. M.; SINGH, S. K.; SZABÓ, S.; SURYAVANSHI, S. Landscape metrics for assessment of land cover change and fragmentation of a heterogeneous watershed. Remote Sensing Applications: Society and Environment, vol. 10, 2018. pp. 224-233.

LAM, N. S. N.; CHENG, W.; ZOU, L.; CAI, H. Effects of landscape fragmentation on land loss. Remote sensing of environment, vol. 209, 2018. Pp.253-262.

LEAL, F. A.; SANTOS FILHO, F. F.; LEAL, G. S. A.; ALMEIDA, M. V. S., MIGUEL, E. P. Análise temporal da fragmentação da paisagem no entorno de florestas nacionais em Rondônia. Nativa, Sinop, vol. 7, n. 1, 2019. pp. 94 - 100. 
LIMA, V. R. P.; SEABRA, V. S.; XAVIER, R. A.; DORNELLAS, P. C. Análise do Padrão Espacial do Uso e Cobertura do Solo e da Fragmentação e Conectividade da Vegetação no Semiárido do Nordeste Brasileiro: Bacias dos Rios Taperoá e Alto Paraíba-Pb. Revista de Estudios Andaluces (REA), n. 37, 2019. pp. 25 - 49.

MCGARIGAL, K.; MARKS, B. J. FRAGSTATS: Spatial pattern analysis program for quantifying categorical maps. Forest Science Department, Oregon State University, Corvallis, 112p, 1995.

MCGARIGAL, K.; TAGIL, S.; CUSHMAN, S. A. Surface metrics: an alternative to patch metrics for the quantification of landscape structure. Landscape Ecology, vol. 24, n. 3, 2009. pp. 433-450.

METZGER, J. P. Estrutura da paisagem e fragmentação: análise bibliográfica. Anais da Academia Brasileira de Ciências. vol.71, n.3, 1999. pp.445-463.

MORAES, A.C.R. Contribuições para a gestão da zona costeira do Brasil: elementos para uma geografia do litoral brasileiro. 2. ed. São Paulo: Annablume,. v. 01. 2007, 232 p.

OLIVEIRA, A. G.; BARROS, L. C. L.; MACHADO, R. A. S.; MOREIRA, I. T. A. Utilização do Sistema de Informação Geográfica-SIG na análise estrutural da vegetação: o exemplo de Salvador, Bahia - Brasil. Brazilian Applied Science Review, vol. 3 n. 2, 2019. pp. 1253 - 1279

OLIVEIRA, L. S.; SOUZA, R. M. Análise Geoecológica da Paisagem Costeira do Município de Aracaju/Sergipe. RA'E GA (UFPR), vol. 42, 2017. pp. 86-103.

PRATA, A. P. DO N.; AMARAL, M. DO C. E.; FARIAS, M. C. V.; ALVES, M. V. (ORGS.). Flora de Sergipe. 1a edição ed. Aracaju: Gráfica e Editora Triunfo, 2013, $592 \mathrm{p}$.

RIBEIRO, M. C.; METZGER, J. P.; MARTENSEN, A. C.; PONZONI, F. J.; HIROTA, M. M. The Brazilian Atlantic Forest: How much is left, and how is the remaining forest distributed? Implications for conservation.

Biological Conservation, vol. 142, n. 6, 2009. pp. 1141-1153.

RODRIGUES, E. Ecologia de fragmentos florestais no gradiente de urbanização de Londrina - PR. Dissertação de Mestrado. Universidade de São Paulo. Programa de Pós-Graduação em Pós Graduação em Ciências da Engenharia Ambiental, São Carlos, 1993. $110 \mathrm{p}$.

SAITO, N. S., MOREIRA, M. A., SANTOS, A. R. D., EUGENIO, F. C., FIGUEIREDO, A. C. Geotecnologia e ecologia da paisagem no monitoramento da fragmentação florestal. Floresta e Ambiente, vol. 23, n. 2, 2016. pp.201 - 210.

SANTOS, R. A. dos; MARTINS, A. A.; NEVES, J. P.; LEAL, R.A. (Orgs.) Geologia e recursos naturais do estado de Sergipe: texto explicativo e mapa geológico do estado de Sergipe. Brasília: CPRM, 1998. $156 \mathrm{p}$. 
SERGIPE. Secretaria de Estado do Planejamento, da Ciência e da tecnologia. Atlas digital sobre os recursos hídricos de Sergipe. Sergipe: SEPLANTEC/SRH, 2011.

SILVA, M. S. F.; SOUZA, R. M. Padrões Espaciais de Fragmentação Florestal na FLONA do IBURA - Sergipe. Mercator, v. 13, n. 3, p. 121-137. 2014.

SOUZA, C. G.; ZANELLA, L.; BORÉM, R. A. T.; DE CARVALHO, L. M. T.; ALVES, H. M. R.; VOLPATO, M. M. L. Análise da fragmentação florestal da área de proteção ambiental Coqueiral, Coqueiral-MG. Ciência Florestal, vol. 24, n. 3, 2014. pp. 631 - 644.

SOUZA, C. R. G. A. Erosão Costeira e os Desafios da Gestão Costeira no Brasil. Revista da Gestão Costeira Integrada vol. 9, n. 1, 2009. pp. $17-37$.

SRH, Superintendência de Recursos Hídricos. Site $<$ http://www.semarh.se.gov.br/srh>, acessado em Outubro de 2016.

TROLL, Carl, "Die geographísche Landschaft und ihre Erforschung" Studim Generale, 1950, traduzido por BRAGA, G.C. Espaço e Cultura, $\mathrm{N}^{\circ} 4$, junho de 1997

TROPPMAIR, H. Perfil ecológico e fitogeográfico do Estado de Sergipe. Biogeografia, n.2, São Paulo, USP/ Instituto de Geografia, 1971.

TURNER, M. G.; O'NEILL, R. V.; GARDNER, R. H.; MILNE, B. T. Effects of changing spatial scale on the analysis of landscape pattern. Landscape Ecology. vol. 3. n. 3/4. 1989. pp. 153- 162.

VOLOTÃO, C. F. S. Trabalho de análise espacial - métricas do Fragstats. Instituto Nacional de Pesquisas Espaciais - INPE - São José dos Campos. 1998. 45p.

WANDERLEY, L. L. Litoral sul de Sergipe: uma proposta de proteção ambiental e desenvolvimento sustentável. Tese de doutoramento. Universidade Estadual Paulista "Júlio de Mesquita Filho", Rio Claro, IGCE, 1998. 421p. 